Research Article

\title{
Fracture fixation of both bone lower third leg using minimally invasive plate osteosynthesis technique - is fixation of fibula necessary
}

\author{
Chaitanya Krishna*, Jayanta Mondal
}

Department of Orthopaedics, Medical College and Hospital, Kolkata, West Bengal, India

Received: 25 December 2015

Revised: 20 March 2016

Accepted: 31 March 2016

*Correspondence:

Dr. Chaitanya Krishna,

E-mail: chatconfident@gmail.com

Copyright: (c) the author(s), publisher and licensee Medip Academy. This is an open-access article distributed under the terms of the Creative Commons Attribution Non-Commercial License, which permits unrestricted non-commercial use, distribution, and reproduction in any medium, provided the original work is properly cited.

\begin{abstract}
Background: Fractures of the distal third tibia and fibula can be challenging to treat because of the limited soft tissue, the subcutaneous location and poor vascularity. The best treatment remains controversial. Specific objectives of this study are mal-alignment in coronal and sagittal plane, rotational deformity and function stability of the ankle joint after fixation of tibia, and to determine the need for fixation of fibula.

Methods: Distal third tibia and fibula fracture were included in the study. Tibia fracture was fixed with distal tibial locking plate using MIPPO Technique. Fibula was fixed in one group using one third tubular plate, consisting of 20 patients and in other group fibula was not fixed which also consist of 20 patients.

Results: In the entire series average valgus angulation in group where fibula was not fixed was 9.6 degree and malrotation was 16.05, while in group where fibula was fixed had valgus angle 5.95 and malrotation angle 7.5.

Conclusions: Fibula fixation is better than without fixation of fibula. Patients with additional fibular stabilization had proper realignment of ankle mortise resulting in less restriction of ankle movement and better functional outcome. . In patients where both tibia and fibula is fixed there is reduced malunion, ankle stiffness, ankle pain and improves functional outcome.
\end{abstract}

Keywords: Mippo technique, Distal third tibia and fibula, Fibula fixation, Distal tibial locking plate

\section{INTRODUCTION}

Surgical fixation of distal tibia and fibula fractures can be difficult, and requires careful preoperative planning, fracture pattern, soft tissue injury, and bone quality critically influence the selection of fixation technique. At the present time, there is controversy regarding fibular fixation whenever tibial plating is contemplated in the unstable distal tibia fibular fracture. The present study will help regarding stability of the ankle joint after fixation of fibula. In cases of fibular fixation in fracture both bone lower leg there is less varus or valgus angulation, less rotational deformity and faster union time. ${ }^{1,2}$ The incidence of mal-union in other series showed average valgus angulation was significantly less in group where fibula was fixed verses group where fibula was not fixed. The degree of rotational malalignment at the ankle in group where fibula was fixed had average 7 degree versus average 15 degrees in group where fibula was not fixed.

Different study reported that fibular plate fixation increased the initial rotational stability after distal tibial fracture in comparison with patients that had tibial fixation alone. Several experimental models of mid-shaft tibia and fibula fractures have suggested there is improved mechanical stability of the tibia with adjuvant fibular fixation. Minimally invasive techniques in distal tibial and fibula fractures are technically feasible and may be advantageous in that it minimizes soft tissue compromise and devascularisation of the fracture fragments. $^{3-5}$ 


\section{METHODS}

The selection criteria are closed fractures and open fractures of gustilo type $I$ in the lower third tibia and fibula fracture in age group 18-75 years. The exclusion criteria are undisplaced distal third fracture both bone lower leg which can be managed conservatively, open fracture of distal third tibia and fibula fracture except gustilo type i, patients with medical co-morbidities not fit for anesthesia, patients with pre-existing deformity and only distal tibial fracture with intact fibula.

Technique of tibia fixation using MIPPO technique: the patient is position supine on a radiolucent operating table with padding under the leg to assist lateral imaging. The image intensifier is placed in the opposite side and rotated for AP and lateral views. A tourniquet is usually not required, but can be applied and inflated later during the operation, if required. The location of the surgical approach depends on the individual soft tissue situation and the fracture pattern as well as what is required for adequate reconstruction of the articular surface of the distal tibia. Generally, the distal tibial locking plate is inserted from distal to proximal through a tunnel between periosteum and intact overlying tissue. The medial approach is commonly used.

However, in selected cases with soft tissue lesion on the medial side an anterolateral approach may be indicated. A straight or slightly curved skin incision is performed on medial aspect of distal tibia. The length of incision varies from $3-5 \mathrm{~cm}$, depending on the type of plate selected. The incision stops distally at the medial malleolus. Separate stab incisions are usually sufficient for insertion of proximal screws in diaphysis. The incision should be carried out straight through the sub-cutaneous fat without developing skin flaps. The greater saphenous vein and saphenous nerve are held anteriorly with blunt retractor. The incision is continued down to the periosteum, which is completely preserved. In this epi-periosteal space tunneling towards the diaphysis can be easily achieved by using the blunt tip of the plate or an epi-periosteal tunneling instrument. By directing the tip of the plate towards the soft tissue the fracture is bypassed without interfering with fracture gaps. First the plate is adjusted to per articular part of the tibia. It is important that the plate is in the correct position in relation to the joint space and an intra-articular K-wire can be used as a guide under image intensifier.

The first $3.5 \mathrm{~mm}$ cortex screw is inserted in one of the most distal plate holes just above the ankle joint, thus approximating the plate to the bone. The general principle is that the simpler the fracture, the more accurate the reduction has to be. Bridging a simple fracture with a gap of more than $2-3 \mathrm{~mm}$ can lead to a delayed or non-union. The reduction is maintained by pointed reduction forceps per cutaneously on each side of the fracture. The plate is now slid through distal approach and preliminary fixed first with cortex screw.
Another threaded drill sleeve is inserted in the most proximal plate hole through the proximal incision. Using drill sleeve as handle, the proximal end plate is placed at the centre of the bone. A $2.7 \mathrm{~mm}$ drill bit is then inserted monocortically or bicortically through the drill sleeve to hold the plate to the bone. After insertion of one screw on each side of the fracture, minor corrections of malalignment in the sagittal plane for flexion extension are still possible. The definite fixation is then completed by inserting additional LHSs.

There should be at least three bicortical screws in the diaphysis and 5-6 with adequate length in epimetaphysis. In general, it is recommended to use more screws in poor bone quality. In case where there are large, displaced intermediate metadiaphyseal fragments on the opposite side of the plate a dependent reduction screw should be fixed to reduce the gap. Complex multi-fragmentary fractures reduction can be achieved over the plate which is first attached to the distal part with one cortex screw close to the ankle joint. This screw should not be fully tightened to allow for indirect reduction manoeuvres using a percutaneously inserted drill sleeve in the most proximal plate holes. Longitudinal, rotational and axial alignment in the frontal plane (valgus-varus) can be achieved using this inserted drill sleeve as a reduction handle. Image intensifier control is used when assessing the correct alignment.

A drill bit is inserted bicortically through this inserted drill sleeve at the proximal end of the plate which has to position in the centre of the bone. The distal screw is tightened and a lateral image intensifier view is utilised to check the correct alignment in the sagittal plane (flexionextension). This can still be corrected quite easily at this stage by bimanual manipulation. Usually, multifragmentary fractures are bridged without interfragmentary lag screw, providing a relative stability. The plates act as a pure internal fixator. At the end of each operation the integrity of syndesmotic ligament must be checked under image intensification using the hook test or the pronation-external rotation manoeuvre .In case of instability, visible in the widening of the medial/ or lateral clear space.

\section{Technique of fibular plating}

The fibular fracture site was palpated and a longitudinal incision of appropriate length centering the fracture was given. The fracture was reduced and held with a $1 / 3^{\text {rd }}$ tubular plate and bone clamp. A hole was drilled through a hole in the plate using neutral drill sleeve. The depth was measured, hole was tapped and a cortical screw applied. Another hole was drilled eccentrically through a hole in the plate nearest to the fracture line in the opposite fragment. The depth was measured, the hole was tapped and a second cortical screw was inserted. Similarly, other cortical screws were inserted but using the neutral drill sleeve. The alternate tightening of the first and second screws resulted in axial compression and stable fracture fixation. 
The wound was thoroughly toileted, hemostasis secured and closed by applying interrupted skin suture. During follow up, patients were evaluated on the following: any specific complain of the patient, clinical assessment, condition of the suture line , movements of the ankle and knee joint, functional abilities ( ability to walk ,shortening, ability to squat or sit cross legged, etc. ) radiological evidence of union any complication and rehabilitation .

\section{RESULTS}

In total, 43 patients underwent tibial plating with or without fibular plating in the Department of Orthopedic Surgery, Medical college and Hospital, Kolkata, were studied. Out of these 43 patients, three were lost to follow-up and these cases were discontinued from the study. The remaining 40 cases were follow-up for an average period of 12 months (range10 -16 months). Only these 40 cases were taken into consideration while analyzing the results of this study. The series included patients between 20 to 72 years of age. Group A is where fibula was not fixed and Group B where fibula was fixed.

In the entire series, average valgus angulation in group where fibula was not fixed was 9.6 degree with standard deviation of 1.66, while in group where fibula was fixed was 5.95 with standard deviation of 1.09 . $\mathrm{P}$ value comes out to be 0.0001 , which is significant, suggestive of fibula fixation is better than without fixation of fibula (Table 1). Malrotation of the distal tibia in group A was 16.05, while mean value in group $\mathrm{B}$ was 7.5 . $\mathrm{P}$ value comes out to be 0.001 , as value was significant which again suggests that fibula fixation is better than without fixation of fibula (Table 2).

Range of motion of ankle joint. It was graded according to the extent of restriction to the normal range of movement of that particular joint, expressed as a percentage of normal. $15(75 \%)$ patients had less than $30 \%$ postoperative restriction of ankle joint movement in group B, while 1 patient had a severe restriction $(>60 \%)$. $4(20 \%)$ patients in group A had at least $60 \%$ restriction of ankle joint movement, only 1 (5\%) patient of group B had such amount of restriction. Patients with additional fibular stabilization had proper realignment of ankle mortise resulting in less restriction of ankle movement (Table 3).

Pain: only four patients had moderate to severe degree of pain. All in group A. Most of these were associated with malrotation or angulation. There were five cases of mild pain, three in group A and two in group B. All of these patients had associated restriction of ankle joint movement (Table 4 and 5).The final follow up result in group A, excellent results were noted in $65 \%$ cases while $85 \%$ recorded in group B; $\mathrm{p}<0.05$ (Table 6). 14 patients were satisfied in group A while 19 patients were satisfied in group B. Poor results was seen in group A while none of the patients were poor in group B (Table 6).

\section{Functional assessment of the patients}

A grading system was formulated to analyze the functional status of the patients after surgery (Table 4 and Table 5).

Pain (40 points)

- $\quad$ None grade 1 - 40

- Mild, occasional grade 2 - 30

- Moderate, daily Severe, almost always present grade $3-0$

Function (50 points) Activity limitations, support requirement

- No limitations, no support - 10

- No limitation of daily activities, limitation of recreational activities, no support - 7

- Limited daily and recreational activities, cane - 4

- Severe limitation of daily and recreational activities, walker, crutches, wheelchair, brace - 0 ,

Maximum walking distance, blocks

- Greater than 6-5,

- 4-6 - (4)

- $1-3-(2)$

- Less than 1-(0)

Walking surfaces

- No difficulty on any surface - 5

- Some difficulty on uneven terrain, stairs, inclines, ladders - 3

- Severe difficulty on uneven terrain, stairs, inclines, ladders - 0

\section{Gait abnormality}

- None, slight - 8,

- Obvious - 4

- $\quad$ Marked - 0,

\section{Sagittal motion (Flexion plus extension)}

- Normal or mild restriction $\left(30^{\circ}\right.$ or more $)-8$

- Moderate restriction $\left(15^{\circ}-29^{\circ}\right)-4$,

- Severe restriction (less than 150) - 0

Hind foot motion (Inversion plus eversion)

- Normal or mild restriction (75\%-100\% normal) - 6

- Moderate restriction (25\%-74\% normal) - 3

- Marked restriction (less than $25 \%$ normal) - 0

Ankle-hindfoot stability (Antero-posterior, varus-valgus)

- $\quad$ Stable - 8 
- Definitely unstable - 0

Alignment (10 points)

- Good, plantigrade foot, midfoot well aligned - 15

- Fair, plantigrade foot, some degree of midfoot malalignment observed, no symptoms - 8
- Poor, nonplantigrade foot, severe malalignment, symptoms - 0

Scoring

For grade I: 90 - 100 points. Excellent

For grade II: 80 - 90 points. Good

For grade III: $<80$ point. Poor

Table 1: Distribution of the patients according to the valgus angle at fracture site.

\begin{tabular}{|llllll|}
\hline $\begin{array}{l}\text { Valgus angle at } \\
\text { fracture site }(\%)\end{array}$ & $\begin{array}{l}\text { Number of } \\
\text { patients }\end{array}$ & $\begin{array}{l}\text { Percentage of } \\
\text { total }(\%)\end{array}$ & $\begin{array}{l}\text { Valgus angle at } \\
\text { fracture site }(\%)\end{array}$ & $\begin{array}{l}\text { Number of } \\
\text { patients }\end{array}$ & $\begin{array}{l}\text { Percentage of } \\
\text { total }(\%)\end{array}$ \\
\hline 5-8 degree (A) & 6 & 30 & $5-8$ degree & 18 & 90 \\
\hline 9-12 degree (B) & 13 & 65 & $9-12$ degree & 2 & 10 \\
\hline $13-16$ degree (C) & 1 & 5 & 13-16 degree & 0 & 0 \\
\hline Total & 20 & 100 & Total & 20 & 100 \\
\hline
\end{tabular}

Table 2: Distribution of the patients according to the malrotation at fracture site.

\begin{tabular}{|llllll|}
\hline $\begin{array}{l}\text { Malrotation at } \\
\text { fracture site (\%) }\end{array}$ & $\begin{array}{l}\text { Number of } \\
\text { patients }\end{array}$ & $\begin{array}{l}\text { Percentage of } \\
\text { total }(\%)\end{array}$ & $\begin{array}{l}\text { Malrotation at } \\
\text { fracture site }(\%)\end{array}$ & $\begin{array}{l}\text { Number of } \\
\text { patients }\end{array}$ & $\begin{array}{l}\text { Percentage of total } \\
(\%)\end{array}$ \\
\hline 5-10 degree (A) & 1 & 5 & $5-10$ degree & 18 & 90 \\
\hline $11-15$ degree (B) & 7 & 35 & $11-15$ degree & 2 & 10 \\
\hline $16-20$ degree (C) & 12 & 60 & $16-20$ degree & 0 & 0 \\
\hline Total & 20 & 100 & Total & 20 & 100 \\
\hline
\end{tabular}

Table 3: Distribution of the patients according to the restriction of movement at ankle joint.

\begin{tabular}{|llllll|}
\hline $\begin{array}{l}\text { Restriction of } \\
\text { movement }(\%)\end{array}$ & $\begin{array}{l}\text { Number of } \\
\text { patients }\end{array}$ & $\begin{array}{l}\text { Percentage of } \\
\text { total }(\%)\end{array}$ & $\begin{array}{l}\text { Restriction of } \\
\text { movements }(\%)\end{array}$ & $\begin{array}{l}\text { Number of } \\
\text { patients }\end{array}$ & $\begin{array}{l}\text { Percentage of } \\
\text { total }(\%)\end{array}$ \\
\hline$<30 \%(\mathrm{~A})$ & 13 & 65 & $<30 \%$ & 15 & 75 \\
\hline $30-60 \%(\mathrm{~B})$ & 3 & 15 & $30-60 \%$ & 4 & 20 \\
\hline$>60 \%(\mathrm{C})$ & 4 & 20 & $>60 \%$ & 01 & 5 \\
\hline Total & 20 & 100 & Total & 20 & 100 \\
\hline
\end{tabular}

Table 4: Distribution of the patients in group A according to the results at final follow-up.

\begin{tabular}{|lllll|}
\hline Criterion & Grade I & Grade II & Grade III & Total \\
\hline Pain & 17 & 3 & 0 & 20 \\
\hline Restriction of ankle joint movement & 13 & 3 & 4 & 20 \\
\hline Malrotation & 1 & 7 & 12 & 20 \\
\hline Valgus angulation & 6 & 13 & 1 & 20 \\
\hline Radiological union time & 3 & 8 & 9 & 20 \\
\hline Patients satisfaction & 14 & 4 & 2 & 20 \\
\hline
\end{tabular}

\section{Final follow - up as per our protocol (Table 4)}

Grading Criteria

I. Pain :

1. Grade 1 - None,

2. Grade 2 - Mild, occasional,
3. Grade 3 - Moderate, daily severe, almost always present,

II. Restriction of ankle joint movement:

1. Grade $1-(<30)$ Degree,

2. Grade 2 - (30-60) Degree, 
3. Grade 3 - (>60) Degree,

III. Malrotation:

1. Grade 1 - (5-10) Degree,

2. Grade 2 - (11-15) Degree,

3. Grade 3 - (16-20) Degree,

IV. Valgus angulation ( lateral distal tibial angle):

1. Grade 1 (5-8) Degree,

2. Grade 2 (9-12) Degree,

3. Grade 3 (13-16) Degree,

V. Radiological union time:

1. Grade $1-(<12)$ Weeks,

2. Grade 2 - (12-14) Weeks,
3. Grade 3 - (>14) Weeks,

VI. Patients satisfaction:

1. Grade 1 - Highly Satisfied,

2. Grade 2 - Satisfied,

3. Grade 3 - Dissatisfied,

Scoring:

For grade I: 3 points.

For grade II: 2 points.

For grade III: 1 point.

Scores of 6 - 10: poor.

Scores of 11 - 14: fair / good.

Scores of 15 - 18: excellent.

Table 5: Distribution of the patients in group B according to the results at final follow-up.

\begin{tabular}{|lllll|}
\hline Criterion & Grade I & Grade II & Grade III & Total \\
\hline Pain & 18 & 2 & 0 & 20 \\
\hline Restriction of ankle joint movement & 15 & 4 & 1 & 20 \\
\hline Malrotation & 18 & 2 & 0 & 20 \\
\hline Valgus angulation & 18 & 2 & 0 & 20 \\
\hline Radiological union time & 4 & 7 & 9 & 20 \\
\hline Patients satisfaction & 19 & 1 & 0 & 20 \\
\hline
\end{tabular}

Table 6: The following table shows the final results of the patients in both the groups.

\begin{tabular}{|llllll|}
\hline & \multicolumn{2}{c}{ Group } & A & \multicolumn{2}{c|}{ Group B } \\
\hline Score & Number of cases & Percentage of total (\%) & Score & Number of cases & Percentage of total (\%) \\
\hline Excellent & 13 & 65 & Excellent & 17 & 85 \\
\hline Good/ Fair & 5 & 24 & Good/ Fair & 3 & 12 \\
\hline Poor & 2 & 16 & Poor & 0 & 8 \\
\hline Total & 20 & 100 & Total & 20 & 100 \\
\hline
\end{tabular}

\section{DISCUSSION}

The incidence of mal-union in other series were as studied by Manish et al showed average valgus angulation was significantly less in group B (average 5 degree) verses group A (average 9 degree ). The degree of rotational malalignment at the ankle in group B was average 7 degree versus average 15 degree in group A. Kumar et al reported that fibular plate fixation increased the initial rotational stability after distal tibial fracture in comparison with patients that had tibial IMN alone. Morin et al in a cadaveric study, show off a significant difference in axial rotation stability when fixing the fibula. Egol et al studied on 72 patients and reported malalignment was lower in the fibular fixation group compared to tibial fixation alone. Bonnevialle et al reported that the tibial axes were statistically better corrected when the fibula was treated with fixation and in our study fibula fixation had an average valgus angulation of 5.95, while without fixation of fibula is 9.6 with standard deviation of $1.66 .^{4-8}$ Hence, it is proved that fibula fixation is better than without fixation of fibula. Manipulative reduction and internal fixation by percutaneous locking compression plate for the treatment of mid-distal tibia-fibula shaft fracture an article by Xia0 YB et al showed that less invasive, more stable fixation, shorter healing time and better functional rehabilitation are observed. ${ }^{9-13}$ The objective of this study was to compare the results of fibular fixation in addition to plate fixation of tibia using MIPO technique in fracture of tibia and fibula distal third and to determine whether any statistical difference existed in the outcome of these two modalities of treatment. Parametric tests like the unpaired t-test were used to compare the quantitative outcomes like time taken for radiological fracture union etc. while non-parametric tests like the Chi-square test were used to compare the qualitative outcomes like incidence of 
mal-union, etc. the results were considered significant if the P-value was less than 0.05. There are certain limitations of this study as well. A larger sample population needed to be studied to reduce the "type II" or beta error of the study. A better method of randomization should have been adopted. The patients could not be followed up for a longer period. Trauma surgery interval needed to be minimized as far as possible. Patients older than 50 years of age are also included. These elderly patients have osteopenic bones. The response to fibular fixation in such patients remains absolutely undetermined via this study.

\section{CONCLUSION}

Patient satisfaction was better in group where fibula was fixed than in the patients of group where fibula was not fixed. Hence, it can be safely concluded that in fracture both bone of lower limb, fibular plate fixation in addition to tibial plating significantly improves the long-term outcome and enhances patient satisfaction.

Funding: No funding sources

Conflict of interest: None declared

Ethical approval: The study was approved by the institutional ethics committee

\section{REFERENCES}

1. Strauss EJ, Alfonso D, Kummer FJ, Egol KA, Tejwani NC. The effect of concurrent fibular fracture on the fixation of distal tibia fractures: a laboratory comparison of intramedullary nails with locked plates. Journal of orthopaedic trauma. 2007;21(3):172-7.

2. Weber TG, Harrington RM, Henley MB, Tencer AF. The role of fibular fixation in combined fractures of the tibia and fibula: a biomechanical investigation. Journal of orthopaedic Trauma. 1997;11(3):206-11.

3. Williams TM, Marsh JL, Nepola JV, DeCoster TA, Hurwitz SR, Bonar SB. External fixation of tibial plafond fractures: is routine plating of the fibula necessary? Journal of orthopaedic trauma. 1998;12(1):16-20.
4. Prasad M, Yadav S, Sud A, Arora NC, Kumar N, Singh S. Assessment of the role of fibular fixation in distal-third tibia-fibula fractures and its significance in decreasing malrotation and malalignment. Injury Elsevier. 2013;44(12):1885-91.

5. Kumar A, Charlebois SJ, Cain EL, Smith RA, Daniels AU, Crates JM. Effect of fibular plate fixation on rotational stability of simulated distal tibial fractures treated with intramedullary nailing. J Bone Joint Surg Am. 2003;85(4):604-8.

6. Morin PM, Reindl R, Harvey EJ, Beckman L, Steffen T. Fibular fixation as an adjuvant to tibial intramedullary nailing in the treatment of combined distal third tibia and fibula fractures: a biomechanical investigation. Can J Surg. 2008;51(1):45-50.

7. Egol KA, Weisz R, Hiebert R, Tejwani NC, Koval $\mathrm{KJ}$, Sanders RW. Does fibular plating improve alignment after intramedullary nailing of distal metaphyseal tibia fractures? Orthop Trauma. 2006;20(2):94-103.

8. Bonnevialle P, Lafosse JM, Pidhorz L, Poichotte A, Asencio G, Dujardin F. The french Society of orthopaedics and traumatology. 2010;96(6):667-73.

9. Xiao YB, Hu DX, Tang QM, Xu ZB, Zhou QK, Deng PZ, et al. Manipulative reduction and internal fixation by percutaneous locking compression plate for the treatment of mid-distal tibiofibula shaft fractures. Zhongguo Gu Shang. 2011;24(5):431-3.

10. Berlusconi M, Busnelli L, Chiodini F, Portinaro N. To fix or not to fix? The role of fibular fixation in distal shaft fractures of the leg. Injury. 2014;45(2):408.

11. Ronga M, Shanmugam C, Longo UG, Maffulli N. Minimally invasive osteosynthesis of distal tibia fractures using locking plates is safe and effective. Orthop Clin North Am. 2009;40(4):499-504.

12. Joveniaux $\mathrm{P}, \mathrm{Ohl} \mathrm{X}$, Harisboure A, Berrichi $\mathrm{A}$, Labatut L, Simon P, et al. Distal tibia fractures: management and complications of 101 cases Int Orthop. 2009;25:23-9.

13. Rouhani, Elmi A, Aghdam AH, Panahi F. Dokht Ghafari. The role of fibular fixation in the treatment of tibia diaphysis distal third fractures orthopaedics and traumatology. Surgery and Research. 2012;98(8):868-72.

Cite this article as: Krishna $\mathrm{C}$, Mondal $\mathrm{J}$. Fracture fixation of both bone lower third leg using minimally invasive plate osteosynthesis technique - is fixation of fibula necessary Int Surg J 2016;3:589-94. 